\title{
Perancangan Objective Structured Clinical Examination (OSCE) untuk Menilai Kompetensi Klinik
}

\author{
Zulharman
}

\begin{abstract}
When planned and organized correctly, OSCE can be highly successful as an instrument to assess competence in medicine. Knowledge about how to plan and organize OSCE is required by OSCE's designers in medical education, so that OSCE which had been designed become valid, reliable and feasible. The elements in designed OSCE consisted of defining of clinical competency which be assessed, design station, patient, examiners, pass or fail scoring, logistics and costs.
\end{abstract}

Keywords : OSCE - design - assessment - clinical competency

Penerapan kurikulum berbasis kompetensi (KBK) bertujuan agar seorang lulusan dokter memiliki kompetensi klinik yang sudah ditetapkan sehingga ia mampu menunjukkan kompetensinya di dunia kerja. Oleh karena itu, untuk memastikan bahwa seorang lulusan dokter tersebut telah memiliki kompetensi klinik yang telah ditetapkan tersebut, maka diperlukan suatu penilaian untuk mengukur kompetensi tersebut. Miller (1990) mengemukakan ada empat level penilaian kompetensi klinik, terdiri dari "knows", "knows how", "shows how" dan "does". Penilaian kompetensi klinik selama ini umumnya menilai pada level "knows" dan "knows how". Penilaian pada level ini tidak bisa memastikan kompetensi yang dimiliki seorang dokter sehingga penilaian kompetensi klinik sampai tingkat "shows how" dan "does" perlu dilakukan. Objective structured clinical examination (OSCE) merupakan penilaian yang sesuai dengan konsep Miller pada level "shows how" ( gambar 1).,

\footnotetext{
Mahasiswa Fakultas Kedokteran Universitas Riau

Bagian Ilmu Penyakit Dalam RSUD Arifin Ahmad, Pekanbaru

Bagian Biokimia Fakultas Kedokteran Universitas Riau Fakultas Kedokteran Universitas Riau, Jl. Diponegoro No.1 Pekanbaru, Riau, 28111,Telp.0761-839264 Fax.0761839265 email: eni93@yahoo.com1
}

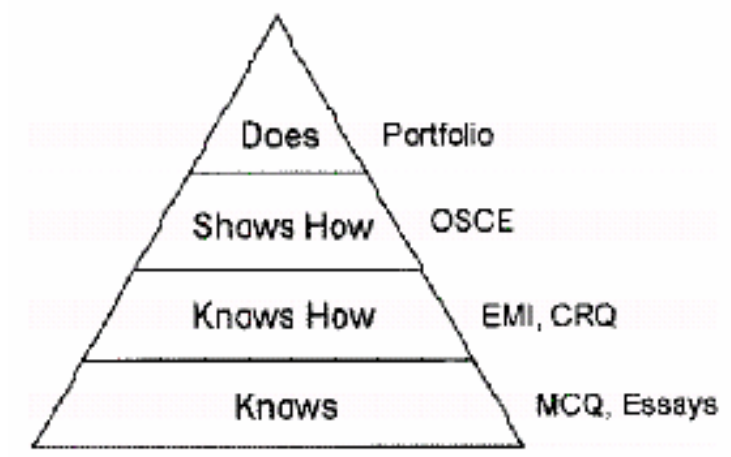

Gambar 1 Miller's pyramide

Association for Medical Education in Europe (AMEE) merekomendasikan untuk penilaian kompetensi seperti pada tabel 1. Dari tabel tersebut terlihat bahwa OSCE dapat menilai clinical skills, practical procedures, patient investigation, patient management, health promotion and disease prevention, communication, information management, principles of social, basic and clinical skills; attitudes, ethics and legal responsibilities; decision making; clinical reasoning and judgement; role as a professional dan personal development. ${ }^{3}$ 
Tabel 1. Komponen kompetensi dan metode penilaiannya (diambil dari Medical Teacher 2003; 25, 6, pp 569)

\begin{tabular}{|c|c|c|}
\hline & Leaming Outcomes & Assessment Methods \\
\hline 1 & Clinical Skills & OSCE; Observation; Logbooks; Written Examination \\
\hline 2 & Aactical Procedures & OSCE; Portfolios; Logbooks; Observation; Written Examination \\
\hline 3 & Patient Investigation & Written Examination; OSCE; Observations Portfolios \\
\hline 4 & Patient Management & Written Examination; OSCE; Observation; Portfolios \\
\hline 5 & $\begin{array}{l}\text { Health Promotion and } \\
\text { Disease Prevention }\end{array}$ & OSCE: Portfolios; Observation; Written Assessment \\
\hline 6 & Communication & OSCEs; Observation; Peer/Self-Assessment; portfolios \\
\hline 7 & Information Management & Skills; Portfolio; OSCE; Observation; Written Examination \\
\hline 8 & $\begin{array}{l}\text { Pinciples of Social, Basic } \\
\text { and Clinical Skills }\end{array}$ & Written Examination; Portfolios; Observation; OSCE \\
\hline 9 & $\begin{array}{l}\text { Attitudes, Ethics and } \\
\text { Legal Responsibilities }\end{array}$ & $\begin{array}{l}\text { Observation; Portfolio; OSCE; Peer/Self-Assessment; Written } \\
\text { Examination }\end{array}$ \\
\hline 10 & $\begin{array}{l}\text { Decision Making; Clinical } \\
\text { Reasoning and Judgement }\end{array}$ & $\begin{array}{l}\text { Portfolio; Observation; Written Assessment; OSCE; Peer/Self- } \\
\text { Assessment }\end{array}$ \\
\hline 11 & Fole as a Professional & $\begin{array}{l}\text { Observation; Peer/Self-Assessment; Portfollo; OSCE; Written } \\
\text { Assessment }\end{array}$ \\
\hline 12 & Personal Development & $\begin{array}{l}\text { Portfolio; Observation; Peer/Self-Assessment; OSCE; Written } \\
\text { Assessment }\end{array}$ \\
\hline
\end{tabular}

\section{PERKEMBANGAN OSCE}

OSCE adalah suatu metode penilaian untuk menilai komponen kompetensi klinik seperti history taking, pemeriksaan fisik, procedural skill, ketrampilan komunikasi, interpretasi hasil laboratorium klinik, manajemen dan terapi dengan mengikuti beberapa station menggunakan checklist yang telah ditetapkan. OSCE pertama kali dikenalkan oleh Harden dari Universitas Dundee pada tahun 1970-an, dalam merespon kelemahan penilaian kompetensi klinik dengan menggunakan sistem konvensional seperti long case examination yang menimbulkan beberapa kelemahan, seperti berbeda mahasiswa akan menghadapi berbeda pasien dan tentu saja berbeda masalah, perbedaan penilaian antara para penilai dalam ketrampilan yang sama, dan tidak diamatinya secara langsung ketika mahasiswa menghadapi pasien. ${ }^{1,4}$

OSCE pertama kali diadopsi oleh Amerika Utara dan lalu berkembang di UK secara luas pada tahun 1990. OSCE sekarang ini digunakan untuk menilai ketrampilan klinik di fakultas kedokteran dan sertifikasi dokter di USA, Canada, UK, Australia, New Zealand, dan negara lain. ${ }^{1,2,4}$

OSCE dapat digunakan untuk menilai kompetensi klinik dari undergraduated dan postgraduated. OSCE dapat digunakan sebagai penilaian formatif untuk memberikan feedback dalam rangka meningkatkan kompetensi klinik mahasiswa. OSCE juga dapat digunakan sebagai penilaian sumatif untuk menentukan kelulusan seorang mahasiswa terhadap kompetensi klinik yang telah ditentukan. ${ }^{1,2,4,5}$

\section{VALIDITAS DAN RELIABILITAS OSCE}

Jumlah station dan lama waktu berlangsungnya OSCE merupakan hal utama yang mempengaruhi reliabilitas OSCE, disamping pengaruh standar pasien, penilaian pribadi, staf yang tidak terorganisasi dan ruangan ujian yang tidak mendukung. Semakin banyak station yang diterlibat maka semakin tinggi reliabilitas dan juga konten validitas dari OSCE. Objektifitas OSCE dapat dilihat dari semua peserta ujian mendapatkan kesempatan yang sama untuk memasuki semua station dan penggunakan checklist penilaian yang sama untuk semua peserta ujian. Penelitian Carraccio dan Englander di University of Maryland School of Medicine menemukan bahwa OSCE valid dan reliabel untuk menilai kompetensi dokter. Penelitian Sloan et al pada residen bedah juga menemukan bahwa OSCE valid dan reliable. ${ }^{1,6,7}$ 


\section{PERANCANGAN OSCE}

Agar OSCE menjadi valid, reliabel dan feasible untuk diterapkan, maka pengetahuan mengenai elemen-elemen yang terlibat dalam perancangan OSCE perlu dikuasai oleh para perancang OSCE di institusi pendidikan kedokteran. Elemen-elemen ini dijabarkan dalam bentuk langkah-langkah untuk merancang OSCE, yaitu :

\section{Penentuan komponen kompetensi klinik yang akan diujikan.}

Penentuan jenis kompetensi yang akan diujikan tergantung dari learning outcome course yang akan dicapai. Pembuatan blue print sangat membantu dalam memilih dan merencanakan jenis ketrampilan yang akan diujikan. Pembuatan blue print ini dilakukan oleh tim yang berhubungan dengan learning objective course. Format blueprint berbentuk matrik yang terdiri dari jenis kompetensi klinik yang akan diujikan (aksis horizontal) dan situasi di mana kompetensi klinik ini didemonstrasikan (aksis vertikal). Komponen kompetensi klinik yang sering diujikan secara garis besar meliputi history taking, pemeriksaan fisik, ketrampilan prosedural, konseling, manajemen dan terapi, interpretasi hasil laboratorium dan radiografi. Situasi dapat berdasarkan satu blok atau sekumpulan blok dalam satu semester, tahun atau fase, bahkan dapat juga untuk OSCE di clinical rotation. Contohnya, blok respirasi, blok kardiovaskuler, blok gastrointestinal, blok urogenital digunakan berdasarkan situasi sekumpulan blok dalam satu semester (lihat tabel 2). Sedangkan bagian bedah, bagian ilmu penyakit dalam, bagian ilmu kesehatan anak, bagian ilmu penyakit kebidanan dan kandungan dan bagian lainnya digunakan pada situasi clinical rotation (lihat tabel 3). ${ }^{1,8,9}$

Proporsi jumlah station dapat disesuaikan dengan kepentingan blok-blok yang terlibat. Contohnya, apabila blok respirasi lebih dipentingkan maka jumlah station untuk blok respirasi dapat lebih banyak dibandingkan blok lain. Hal serupa juga dapat dilakukan pada proporsi jenis kompetensi klinik, dimana apabila ada kompetensi klinik yang perlu ditekankan maka kompetensi klinik ini dapat lebih banyak stationnya dibandingkan kompetensi klinik lain. Contohnya, OSCE untuk tahun pertama kemungkinan lebih menekankan pada history taking dan pemeriksaan fisik dasar daripada manajemen dan terapi. Akan tetapi perlu diperhatikan bahwa penyebaran komponen kompetensi dan blok-blok hendaknya merata sehingga reliabilitas dan validitas menjadi lebih tinggi. ${ }^{1,8,9}$

Tabel 2. Contoh blue print dengan situasi sekumpulan blok dalam 1 semester

\begin{tabular}{|l|c|c|c|c|c|}
\hline & $\begin{array}{l}\text { History } \\
\text { taking }\end{array}$ & $\begin{array}{l}\text { Pemeriksaan konseling } \\
\text { fisik }\end{array}$ & $\begin{array}{l}\text { Frocedural } \\
\text { skill }\end{array}$ & Manajemen & $\begin{array}{l}\text { Interpretasi } \\
\text { data }\end{array}$ \\
\hline $\begin{array}{l}\text { Blok respirasi } \\
\begin{array}{l}\text { Blok } \\
\text { cardiovaskuler }\end{array}\end{array}$ & 1 & 1 & 1 & & 1 \\
\hline $\begin{array}{l}\text { Blok } \\
\begin{array}{l}\text { Gastrointestinal } \\
\text { Blok urogenital }\end{array}\end{array}$ & 1 & & & 1 & \\
\hline
\end{tabular}

Tabel 3. Contoh blue print dengan situasi clinical rotation

\begin{tabular}{|c|c|c|c|c|c|c|}
\hline & $\begin{array}{l}\text { History } \\
\text { taking }\end{array}$ & $\begin{array}{l}\text { Pemeriksaan } \\
\text { fisik }\end{array}$ & konseling & $\begin{array}{l}\text { Procedural } \\
\text { skill }\end{array}$ & Manajemen & $\begin{array}{l}\text { Interpretasi } \\
\text { data }\end{array}$ \\
\hline $\begin{array}{l}\text { Bagian I. Peny. } \\
\text { Dalam } \\
\text { Bagian I. B edah } \\
\text { Bagian I. Kes. } \\
\text { Anak }\end{array}$ & 1 & $\begin{array}{l}1 \\
1 \\
1\end{array}$ & & 1 & 1 & 1 \\
\hline $\begin{array}{l}\text { Bagian I. } \\
\text { Kebidanan dan } \\
\text { kandungan }\end{array}$ & & 1 & 1 & 1 & & \\
\hline
\end{tabular}




\section{Perancangan station}

a. Penentuan jumlah station dan waktu tiap station.

Penentuan jumlah station yang terlibat tidak ada ketentuan yang pasti. Semakin banyak jumlah station maka semakin tinggi reliabilitas OSCE (Petrusa 2002). Schumway dan Harden (2003) menyatakan bahwa untuk memenuhi minimal realibitas diperlukan minimal 20 station. Oleh karena pertimbangan feasibilitas penerapan OSCE dengan 25 station tidak feasible sehingga penerapan OSCE dengan 10-12 station dapat diterima. Hal ini didukung dari hasil penelitian penerapan OSCE di Kanada untuk high stake test, tidak menunjukkan penurunan reliabilitas ketika menggunakan hanya 12 station. ${ }^{1,8,9}$

Penentuan waktu tiap station dipengaruhi oleh kompleksitas ketrampilan yang akan diujikan. Waktu yang sering dipilih berkisar antara $4-15$ menit dan rata-rata yang sering diterapkan adalah 5-8 menit. Hal yang perlu diperhatikan adalah kecukupan waktu yang telah ditentukan tersebut apakah sesuai dengan tugas yang akan dilakukan, sehingga peserta ujian tidak merasa kekurangan waktu dan tergesagesa dalam melakukannya. Hubungan waktu dan jumlah station berkaitan dengan masalah feasibilitas, dimana semakin lama waktu pelaksanaan OSCE dan semakin banyak jumlah station yang dibutuhkan untuk OSCE, maka akan mempengaruhi ketersediaan sumber daya dan fasilitas yang diperlukan. Untuk menghindari jumlah station yang banyak, maka perlu strategi dalam pemilihan station. Station yang lebih menekankan pada written test (static station) dapat dipertimbangkan agar dikeluarkan dan dilakukan dengan tes konvensional di hari lain. . $^{1,89}$

b. Pembuatan skenario, instruksi, scoring checlist dan daftar peralatan untuk station

Pembuatan skenario untuk tiap station dilakukan oleh para ahli sesuai dengan bidangnya. Dalam membuat skenario ini, para ahli membuatnya berdasarkan kasus sebenarnya yang dialami para ahli di klinik. Tahap -tahap untuk membuat skenario adalah :

\section{- Menentukan tujuan station.}

Tujuan station ditentukan dengan menentukan jenis skill dan domain yang akan diuji untuk satu station. Contoh, jenis skill adalah pemeriksaan fisik dan domainnya adalah blok respirasi. Sehingga tujuan station ini adalah untuk menilai kemampuan peserta ujian dalam melakukan pemeriksaan fisik paru-paru.

- Menentukan instruksi untuk peserta ujian, penilai dan standar pasien.

Instruksi untuk peserta ujian harus dibuat ringkas dan jelas sehingga tidak menimbulkan kebingungan dan kesalahpengertian dalam melakukan tugas yang diinstruksikan. Instruksi mengenai kasus yang harus diperankan oleh standar pasien harus diberikan secara jelas dan juga penjelasan mengenai data yang relevan dengan kasus tersebut. Instruksi ini akan dilatihkan ketika pelatihan standar pasien. Penilai juga harus dibuatkan penjelasan mengenai tujuan station, tugas yang harus dilakukan oleh penilai. Penjelasan ini dapat diberikan ketika pelatihan penilai.

\section{- Membuat scoring checklist}

Checklist dibuat lengkap tetapi ringkas dan jelas. Pembobotan nilai terhadap suatu item dapat dilakukan bila item tersebut dirasakan lebih penting dari item yang lain.

- Pembuatan daftar list alat yang digunakan di station tersebut.

\section{Penentuan pasien.}

Pasien yang digunakan dalam OSCE dapat berupa manekin, pasien sesungguhnya (real patient), pasien simulasi atau pasien standar. Penggunaan pasien sesungguhnya dalam OSCE sangat baik dalam memberikan gambaran kasus sebenarnya, akan tetapi memiliki banyak kelemahan, yaitu pasien sesungguhnya memiliki keterbatasan melayani tidak banyak peserta ujian dan pengawasan yang ketat terhadap keadaan pasien tersebut selama OSCE. Inform consent dan izin dari dokter yang menangani pasien perlu dilakukan untuk menghindari hal yang tidak diinginkan. ${ }^{1,8,9}$

Oleh karena keterbatasan dan resiko dalam menggunakan pasien sesungguhnya maka penggunaan pasien simulasi atau pasien standar lebih memberikan kemudahan. Perbedaan pasien simulasi dengan pasien standar terletak pada adanya pelatihan untuk menstandarkan respon pasien terhadap perlakuan peserta ujian. Pasien standar ini 
merupakan orang sehat yang dilatih untuk memerankan keadaan pasien sesuai dengan skenario yang akan diujikan sehingga pasien standar memberikan respon yang konsisten terhadap perlakuan dari peserta-peserta OSCE. Sedangkan pasien simulasi adalah pasien simulasi yang tidak distandarkan atau pasien yang pernah mengalami keadaan seperti skenario dan ia diminta untuk mengimprovisasi sendiri dalam merespon perlakuan dari peserta ujian. Perekrutan pasien standar ini dapat dilakukan dari karyawan institusi sendiri atau dari luar institusi. Pelatihan dilakukan sesuai dengan skenario yang akan diperankan dan lamanya pelatihan bervariasi tergantung kompleksitas skenario station tersebut. Hal yang perlu dipertimbangkan dalam penggunaan pasien standar, yaitu pasien standar tidak dapat dilatih untuk memerankan keadaan seperti pembesaran hati (hepatomegali), suara murmur jantung, suara amphorik pada paru dan hal lainnya yang tidak memungkinkan pasien standar untuk menirukannya. Oleh karena itu strategi dalam pemilihan dan penggunaan pasien agar sesuai dengan skenario perlu dipertimbangkan dalam hal kapan harus memilih dan menggunakan manekin, real atau pasien standar. ${ }^{1,8,9,10}$

\section{Penentuan tim penilai}

Tim penilai dipilih berdasarkan keahliannya untuk masing-masing station.. Penyediaan tim penilai cadangan perlu dilakukan untuk menghindari tim penguji yang sudah ditunjuk berhalangan hadir. Pelatihan diperlukan untuk memberikan penjelasan maksud station yang diujikan, checklist yang digunakan dan cara memberikan feedback. Perekrutan tim penilai dilakukan seminggu atau sebulan sebelum ujian OSCE dilakukan. ${ }^{1,8,9}$

\section{Penentuan Standar kelulusan}

Penentuan standar setting untuk memutuskan nilai cut off seseorang mahasiswa lulus atau tidak lulus dapat menggunakan criterion reference dengan metode Ang off atau metode borderline. Penggunaan metode Ang off memerlukan administrasi dan memakan waktu yang lama sehingga metode borderline lebih feasible untuk digunakan. ${ }^{1,8,9,11,12}$

\section{Logistik}

\section{a. Lokasi dan ruangan}

Lokasi ujian dapat dilakukan di rumah sakit atau di laboratorium ketrampilan klinik (skill labs). Jumlah peserta ujian dan jumlah ruangan yang tersedia menentukan berapa banyak track (satu track terdiri dari seluruh station yang diujikan) dan berapa kali pengulangan track tersebut. Contoh, kita memiliki 60 peserta ujian yang akan mengikuti OSCE 10 station (satu track terdiri dari 10 station) dan setiap station berlangsung selama 8 menit. Kita akan mengatur OSCE berjalan dengan dua track secara paralel sehingga dapat mengakomodasi 20 peserta ujian dalam satu waktu. Dengan menjalankan dua track paralel ini sebanyak tiga kali maka kita telah dapat mengakomodasi 60 peserta ujian dalam satu hari pelaksanaan. ${ }^{1,8,9}$

\section{b. Alarm (bel, buzzer)}

Bel atau buzzer diperlukan untuk sistem perpindahan station. Penggunaan bell dengan sistem computerisasi lebih memberikan konsistensi waktu dari pada menggunakan bel secara manual. Bell dengan sistem computerisasi dapat diatur interval waktunya sesuai dengan keingginan dan juga dapat memberikan variasi bunyi sehingga dapat dengan mudah digunakan untuk membedakan kapan mahasiswa masuk ruangan dan kapan mahasiswa keluar ruangan. Penggunaan bel secara komputerisasi dapat menghemat biaya yang diperlukan untuk penyediaan staf untuk bel secara manual dan juga meningkatkan reliabilitas. ${ }^{1,89}$

\section{c. Equipment dan models}

Penyediaan peralatan dan model yang diperlukan selama OSCE perlu diperhatikan terutama station yang tidak menggunakan pasien standar. Model atau manekin yang digunakan sebagai pasien harus diperiksa kondisinya. Penyiapan cadangan manekin perlu dilakukan untuk menjaga apabila selama OSCE ada manekin yang tidak berfungsi. ${ }^{1,9}$

\section{d. Supporting staff}

Supporting staf yang terlibat di dalam OSCE 
terdiri dari staf untuk administrasi/registrasi peserta, staf untuk menyediakan peralatan OSCE, staf yang bertugas membunyikan bel apabila menggunakan bel secara manual, staf untuk menjaga keamanan dan staf pendukung lainnya yang berhubungan dengan pelaksanaan OSCE. ${ }^{1,8,9}$

\section{Biaya.}

Komponen biaya yang diperlukan dari perancangan OSCE hingga pelaksanaan OSCE sebaiknya telah disusun pada awal perancangan. OSCE memerlukan biaya yang diperlukan untuk honor standar pasien, penguji dan staf pendukung. 1,9

\section{KESIMPULAN}

Pengetahuan mengenai elemen-elemen yang terlibat dalam perancangan OSCE perlu dikuasai oleh para perancang OSCE di institusi pendidikan kedokteran agar OSCE yang dirancang menjadi valid, reliabel dan feasible untuk diterapkan. Komponen yang perlu diperhatikan dalam merancang OSCE meliputi penentuan komponen kompetensi klinik yang akan diujikan, perancangan station, penentuan pasien, penentuan tim penilai, penentuan standar kelulusan, logistik dan biaya.

\section{DAFTAR PUSTAKA}

1. Dent JA, Harden RM, Editors. A Practical Guide For Medical Teachers. Elsevier Churchill Livingstone, 2006.

2. Margery H. Davis. OSCE: the Dundee experience. Medical Teacher 2003 May; 25 (3) : 255-261

3. Shumway J M and Harden R M. AMEE Medical Education Guide No 25: The assessment of learning outcomes for the competent and reflective physician. Medical Teacher 2003; 25, 6 , pp 569-584
4. Amin, ZE., Eng, K.H., (2003). Basics in Medical Education, World Scientific, Singapore.

5. Townsend, AH, Mcllvenny, S., Miller, C.J, \& Dunn, E.V. The use of an objective structured clinical examination (OSCE) for formative and summative assessment in a general practice clinical attachment and its relationship to final medical school examination performance. Medical Education 2001;35:841 \pm 846

6. Sloan,DA, Donnelly, M.B, Schwartz, R.W, and Strodel, W.E. The Objective Structured Clinical Examination. The new gold standard for evaluating postgraduate clinical performance.Ann Surg. 1995 December; 222(6): 735-742.

7. Barman, A. Critiques on objective structure clinical examination. Add Acad Med Singapore 2005; 34: 478-82

8. Sydney Smee. $A B C$ of learning and teaching in medicine Skill based assessment. Bmj Volume 32629 March 2003

9. Twelve tips for organizing an objective structure clinical examination (OSCE)., By: Harden, RM., Medical Teacher, 0142159X, Sep90, Vol. 12, Issue $3 / 4$

10. Adamo, G. Simulated and standardized patients in OSCEs: achievements and challenges 19922003. Medical Teacher 2003 May; 25 (3) : 262 270

11.Kramer, A., Muijtjens, A, Jansen, K.,et all. Comparison of a rational and an empirical standard setting procedure for an OSCE. Medical Education 2003; 37:132-139

12.Alistair M S Chesser, Malcolm R Laing, Zosia H Miedzybrodzka, Julie Brittenden \& Steven D Heys. Factor analysis can be a useful standard setting tool in a high stakes OSCE assessment. Medical Education 2004; 38: 825-831 